Disclosure of Interests: Luciano Lo Giudice: None declared, Maria Laura Acosta Felquer: None declared, Maria Laura Galimberti: None declared, Luis Mazzuoccolo: None declared, Enrique Soriano Grant/research support from: AbbVie, Eli Lilly, GlaxoSmithKline, Novartis, Pfizer Inc, Sandoz, Consultant of: AbbVie, Eli Lilly, GlaxoSmithKline, Novartis, Pfizer Inc, Sandoz, Speakers bureau: AbbVie, Amber, Bristol-Myers Squibb, Eli Lilly, Novartis, Pfizer Inc, Roche DOI: 10.1136/annrheumdis-2020-eular.4805

\section{SAT0427 COMPARATIVE EFFECTIVENESS OF TOFACITINIB (TF) AND ADALIMUMAB (ADA) IN PSORIATIC ARTHRITIS (PSA) PATIENTS IN REAL CLINICAL PRACTICE.}

E. Loginova ${ }^{1}$, T. Korotaeva ${ }^{1}$, E. Gubar ${ }^{1}$, Y. Korsakova ${ }^{1}$, S. Glukhova ${ }^{1}$, E. Vasilenko ${ }^{2}$, A. Vasilenko ${ }^{3}$, N. Kuznetsova ${ }^{4}$, I. Patrikeeva ${ }^{5}$ on behalf of RU-PsART Study Group. ${ }^{1}$ Nasonova Research Institute of Rheumatology, Moscow, Russian Federation; ${ }^{2}$ St. Petersburg Clinical Rheumatology Hospital No.25, St. Petersburg, Russian Federation; ${ }^{3}$ Novgorod Regional Clinical Hospital, Novgorod, Russian Federation; ${ }^{4}$ City Clinical Hospital No. 40, Ekaterinburg, Ekaterinburg, Russian Federation; ${ }^{5}$ Tyumen Regional Clinical Hospital No.1, Tyumen, Russian Federation

Background: Tofacitinib (TF) is an oral Janus kinase inhibitor approved for PsA treatment. It has demonstrated comparable to ADA efficacy in RCT in reducing PsA clinical symptoms ${ }^{1,2}$. There is currently no data concerning comparative effectiveness of TF and ADA in clinical practice. The Russian PsA RegisTry (RU-PsART) collected data from 43 rheumatology centers of the Russian Federation.

Objectives: to study responses to TF or ADA over a period of 6 months (mo) treatment in patients (pts) with active PsA in real clinical practice.

Methods: $77(\mathrm{M} / \mathrm{F}=43 / 34) \mathrm{PsA}$ pts fulfilling the CASPAR criteria from the RU-PsART cohort were divided into two groups according to the treatment given. $41 \mathrm{pts}(\mathrm{M} / \mathrm{F}=24(58.5 \%) / 17(41.5 \%)$, mean age $42.4 \pm 10,3$ years (yrs), median (Me) PsA duration 72 [35;120] mo were treated with TF $5 \mathrm{mg}$ twice daily. 36 pts $(\mathrm{M} / \mathrm{F}=19(52.8 \%) / 17(47.2 \%)$, mean age $44 \pm 11.5 \mathrm{yrs}$, Me PsA duration 59 [22;102] mo were treated with ADA $40 \mathrm{mg} / 2$ weeks, subcutaneous, as a first-line bDMARD. In TF/ADA groups $89 \% / 52.8 \%$ pts accordingly were given combination therapy with Methotrexate (MTX). At baseline (BL) and at 6 mo of therapy PsA activity by DAPSA, BASDAI, the number of pts (NPts) with dactylitis, enthesitis by LEI, BSA, HAQ were evaluated in both groups. At 6 mo of therapy the NPts who achieved remission by DAPSA ( $\leq 4)$ /Low activity (LA) $\leq 14)$ and Minimal disease activity (MDA, 5 of 7) were calculated in both groups. M $\pm S D$, Me [Q25; Q75], Min-Max, \%, t-test, Pierson- $x^{2}$, Manna-Whitney, Wilcoxon tests were performed. All $p<0.05$, were considered to indicate statistical significance.

Results: At BL TF pts had higher PsA activity by DAPSA compared to ADA group: $44.2[37.8 ; 55.3] / 35.8[21.1 ; 52]$ accordingly $(p=0.03)$. At 6 mo of treatment DAPSA significantly decreased in TF/ADA groups - to $11[4,3 ; 17,3] / 9,1[6 ; 19,6]$ $(p<0,001)$ accordingly. At 6 mo of therapy there were no significant differences between groups in achieving MDA, DAPSA LA/Remission (table 1). At 6 mo of treatment in TF-treated group the NPts with dactylitis significantly decreased from $22(53,7 \%)$ to $5(13,2 \%)$ pts $(\mathrm{p}<0.001)$, and in ADA-treated group no significant differences were found in NPts with dactylitis [despite a quantitative decrease from $13(36,1 \%)$ to $6(20 \%)$ pts $(p=0.15)$ ]. The NPts with enthesitis in both TF/ ADA groups decreased significantly: from $27(69,2 \%)$ to $12(30,8 \%)(p<0,002)$ and from $16(72,7 \%)$ to $5(38,5 \%)(p<0.046)$ pts accordingly. In TF/ADA-treated pts BASDAl improved from $6[4.2 ; 7]$ to $1.4[0.6 ; 3.2](p<0.001) /$ from $4.4[1.9 ; 5.8]$ to $3[0.8 ; 4.5]$ accordingly $(p<0.046)$; HAQ significantly decreased from $1[0.625 ; 1.5]$ to $0,5[0 ; 0.875]$ and from $0.875[0.5 ; 1.38]$ to $0.5[0 ; 0.875]$ accordingly. The NPts with $\mathrm{BSA}>3 \%$ significantly reduced in the TF group: from $20(51,3 \%)$ to $8(26,7 \%)$ pts $(p<0,002)$, but not in the ADA group.

Table 1. MDA, DAPSA LA/Remission in TF/ADA at 6 mo

\begin{tabular}{|c|c|c|c|c|c|c|}
\hline \multirow[b]{2}{*}{ Study } & \multicolumn{2}{|c|}{ TF } & \multicolumn{2}{|c|}{ ADA } & \multirow[b]{2}{*}{ OR (95\% Cl) } & \multirow[b]{2}{*}{$P$} \\
\hline & Events & Subjects & Events & Subjects & & \\
\hline $\begin{array}{l}\text { DAPSA remission abs, } \\
\% \text { achieved }\end{array}$ & $\begin{array}{c}11 \\
(26,8 \%)\end{array}$ & 41 & $\begin{array}{c}6 \\
(20,8 \%)\end{array}$ & 29 & $\begin{array}{c}1,406 \\
(0,453-4,366)\end{array}$ & 0.556 \\
\hline $\begin{array}{l}\text { DAPSA LA abs, \% } \\
\text { achieved }\end{array}$ & $\begin{array}{c}15 \\
(36,6 \%)\end{array}$ & 41 & $\begin{array}{c}13 \\
(44,8 \%)\end{array}$ & 29 & $\begin{array}{c}0,710 \\
(0,269-1,872)\end{array}$ & 0.489 \\
\hline MDA abs, $\%$ achieved & $\begin{array}{c}16 \\
(40 \%)\end{array}$ & 40 & $\begin{array}{c}9 \\
(30 \%)\end{array}$ & 30 & $\begin{array}{c}1,556 \\
(0,569-4,249)\end{array}$ & 0.389 \\
\hline
\end{tabular}

Conclusion: In real clinical practice TF and ADA demonstrated comparable effectiveness in all clinical domains of active PSA and showed equal result in achievement of MDA/LA/Remission according to DAPSA

References:

[1] Mease P, Hall S, FitzGerald O, et al. N Engl J Med 2017;377:1537-50.

[2] Gladman D, Rigby W, Azevedo VF, et al. N Engl J Med 2017;377:1525-36.

Acknowledgments: no
Disclosure of Interests: Elena Loginova Speakers bureau: Janssen, Tatiana Korotaeva Consultant of: Pfizer, MSD, Novartis, AbbVie, Celgene, JSC BIOCAD, Janssen, UCB, Lilly and Novartis-Sandoz, Speakers bureau: Pfizer, MSD, Novartis, AbbVie, Celgene, JSC BIOCAD, Janssen, UCB, Lilly and Novartis-Sandoz, ELENA GUBAR: None declared, Yulia Korsakova: None declared, Svetlana Glukhova: None declared, Elizaveta Vasilenko: None declared, Aleksey Vasilenko: None declared, Natalia Kuznetsova: None declared, Irina Patrikeeva: None declared

DOI: 10.1136/annrheumdis-2020-eular.1818

\section{SAT0428 IN PATIENTS WITH PSORIATIC ARTHRITIS IN REAL- WORLD SETTING.}

M. Martin Lopez ${ }^{1}$, B. Joven-Ibáñez ${ }^{1}$, J. L. Pablos ${ }^{1} .{ }^{1}$ Hospital Universitario 12 de Octubre, Madrid, Spain

Background: Secukinumab (SEC) has provided efficacy in clinical trials in patients with psoriatic arthritis (PsA). In PsA patients, a gain in response has been suggested by dose escalation from 150 to $300 \mathrm{mg}$ in the open phase of the FUTURE study ${ }^{1}$.

Objectives: To analyze the usefulness of dose escalation of SEC from 150 to 300 in patients with non-responding PsA to $150 \mathrm{mg}$ in real-world setting.

Methods: Multicentric observational, longitudinal, retrospective study conducted in a tertiary hospital between January 2016 and December 2019. Patients with PSA (CASPAR criteria) receiving at least one dose of SEC were included. Medical records were reviewed to collect demographic and clinical data related to PsA (including activity assessment and treatment). Descriptive statistics and a comparative analysis of the efficacy of SCK by the Student $t$ test in the different dose groups and by the ANOVA test to compare the response between the three dose groups were performed.

Results: 98 patients with PsA treated with SEC, of which $69(70 \%)$ female were included. Mean age was 54 y.o (SD12) and average duration of the disease was 9 (SD 7) years. Three groups were made according to the dose received, SEC150, SEC300 and SEC150-300 (non-responders after SEC150 onset increasing to $300 \mathrm{mg}$ ). The SEC150 group includes $58(59 \%)$ patients of whom $32(55 \%$ ) had received at least one biological (16 one biological, 8 two biological and 10 three or more). The survival of SEC was 1.3 (SD1) years and was suspended in $24(41 \%)$ patients, due to primary failure in 9 , secondary failure 10 , adverse events 4 and allergy to latex 1 . The SEC300 group includes $12(12 \%)$ patients of whom $10(83 \%)$ had received at least one biological ( 1 one biological, 3 two and 6 three or more). The survival of the SEC was 1.6 SD (1.3) years and was suspended in $8(67 \%)$ patients, due to primary failure in 2 , secondary failure 5 and remission 1 . Finally, the SEC150300 group includes 28 (29\%) patients of whom $17(61 \%)$ had received at least one biologic ( 7 one biologic, 2 two and 8 three or more). The survival of the SEC was 1.6 (SD0.9) years and was suspended in 13 (46\%) patients, all due to secondary failure. $54 \%$, therefore, maintains the SCK after responding to the dose increase. The average time of dose increase to $300 \mathrm{mg}$ was 9 (SD6) months. In the three treatment groups, a significant decrease in the values of CRP, ASDAS-CRP and DAPSA was observed at 6 months of SEC (Table 1) However, when comparing the difference of means obtained during follow-up ( $\triangle \mathrm{CRP}, \triangle \mathrm{ASDAS}$ and $\triangle \mathrm{DAPSA}$ ) between the 3 dose groups, no significant differences were found $(p=0.76$ for CRP, $p=0.86$ for ASDAS and $p=0.35$ for DAPSA).

Table 1. Disease activity assessment at 6 months of SEC therapy.

\begin{tabular}{lcccc}
\hline & Baseline & 6 months after SEC & Mean difference & $\mathrm{p}$ value \\
\hline CRP300 (mg/L) & $9 \pm 8,3$ & $4,7 \pm 3,7$ & $-4,3($ IC95\% $-8,9$ a 0,2$)$ & $\mathrm{p}=0,06$ \\
CRP150 $(\mathrm{mg} / \mathrm{L})$ & $7,3 \pm 9,1$ & $4,0 \pm 4,7$ & $-2,9(\mathrm{IC} 95 \%-4,7 \mathrm{a}-1,3)$ & $\mathrm{p}=0,0009$ \\
CRP150-300(mg/L) & $9,9 \pm 11$ & $6,0 \pm 7,4$ & $-3,9(\mathrm{IC} 95 \%-6,9 \mathrm{a}-8,5)$ & $\mathrm{p}=0,0142$ \\
ASDAS-CRP300 & $2,3 \pm 0,7$ & $1,6 \pm 0,6$ & $-0,6(\mathrm{IC} 95 \%-0,9 \mathrm{a}-0,3)$ & $\mathrm{p}=0,0014$ \\
ASDAS-CRP150 & $2,3 \pm 0,6$ & $1,6 \pm 0,7$ & $-0,7(\mathrm{IC} 95 \%-0,8 \mathrm{a}-0,5)$ & $\mathrm{p}<0,0001$ \\
ASDAS-CRP150-300 & $2,2 \pm 0,6$ & $1,6 \pm 0,7$ & $-0,6(\mathrm{IC} 95 \%-0,8 \mathrm{a}-0,4)$ & $\mathrm{p}<0,0001$ \\
DAPSA300 & $33,7 \pm 19,3$ & $16,9 \pm 10,6$ & $-16,8(\mathrm{IC} 95 \%-29,6 \mathrm{a}-3,9)$ & $\mathrm{p}=0,01$ \\
DAPSA150 & $27,4 \pm 11,4$ & $15,4 \pm 10,4$ & $-11(\mathrm{IC} 95 \%-14,4 \mathrm{a}-7,6)$ & $\mathrm{p}<0,0001$ \\
DAPSA150-300 & $28 \pm 9,9$ & $15,8 \pm 8,7$ & $-12,2(\mathrm{IC} 95 \%-15,3 \mathrm{a}-9,1)$ & $\mathrm{p}<0,0001$
\end{tabular}

CRP300: C-reactive protein in patients with SCK $300 \mathrm{mg}$, CRP150: in patients with SCK 150, CRP150-300: in patients with dose escalation from 150 to 300 (same for ASDAS-CRP and DAPSA), SEC: secukinumab

Conclusion: There are no significant differences in the response evaluated by CRP, ASDAS-CRP and DAPSA between the dose of 150 and $300 \mathrm{mg}$ of SEC However, both doses of treatment provided efficacy in clinical practice with significant reduction of activity parameters. In the case of patients not responding to SEC150 mg and prior failure to TNFi, increasing the dose to $300 \mathrm{mg}$ could be an effective option. 